\title{
Corrigendum
}

\section{Corrigendum to "Effects of Canned Pineapple Consumption on Nutritional Status, Immunomodulation, and Physical Health of Selected School Children"}

\author{
Mavil May C. Cervo $\mathbb{C D}^{1}{ }^{1}$ Luisito O. Llido, ${ }^{1,2}$ Erniel B. Barrios, ${ }^{3}$ and Leonora N. Panlasigui ${ }^{1}$ \\ ${ }^{1}$ School of Nutrition, Philippine Women's University, 1004 Manila, Philippines \\ ${ }^{2}$ Clinical Nutrition Services, St. Luke's Medical Center, 1102 Quezon City, Philippines \\ ${ }^{3}$ School of Statistics, University of the Philippines-Diliman, 1101 Quezon City, Philippines \\ Correspondence should be addressed to Mavil May C. Cervo; mavil_may.cervo@yahoo.com
}

Received 16 May 2019; Accepted 26 May 2019; Published 1 July 2019

Copyright (C) 2019 Mavil May C. Cervo et al. This is an open access article distributed under the Creative Commons Attribution License, which permits unrestricted use, distribution, and reproduction in any medium, provided the original work is properly cited.

In the article titled "Effects of Canned Pineapple Consumption on Nutritional Status, Immunomodulation, and Physical Health of Selected School Children" [1], the Conflicts of Interest section should read as follows.

"The authors declare that Del Monte Philippines, Inc. (DMPI) provided the canned pineapple and financial support but had no role in the design and conduct of the study; collection, analysis, and interpretation of the data; preparation and review of the manuscript; and decision to publish. Dr. Panlasigui previously conducted studies for DMPI on a juice drink, ending in 2010.”

\section{References}

[1] M. M. C. Cervo, L. O. Llido, E. B. Barrios, and L. N. Panlasigui, "Effects of canned pineapple consumption on nutritional status, immunomodulation, and physical health of selected school children," Journal of Nutrition and Metabolism, vol. 2014, Article ID 861659, 9 pages, 2014. 


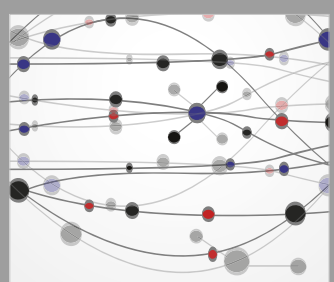

The Scientific World Journal
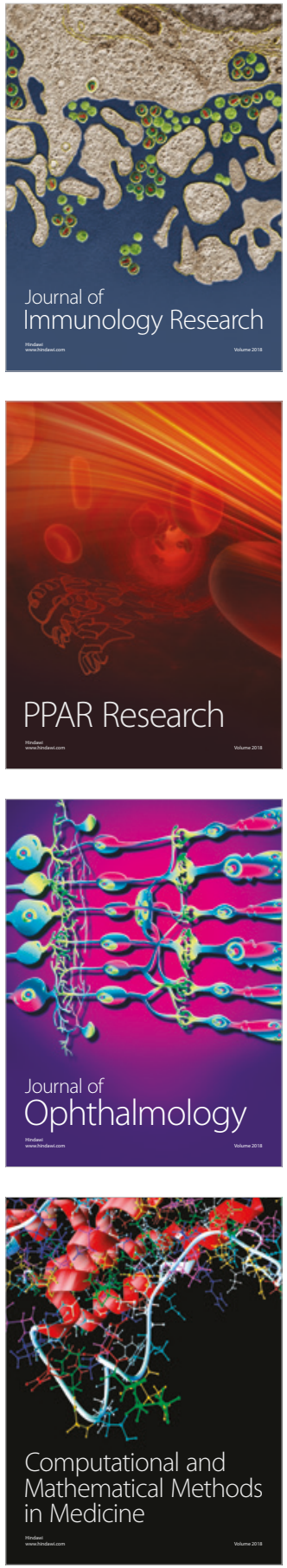

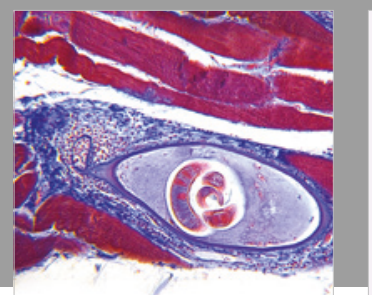

Gastroenterology Research and Practice

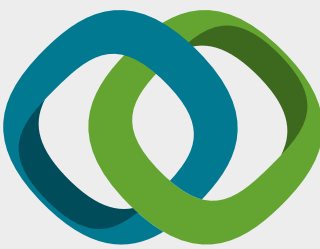

\section{Hindawi}

Submit your manuscripts at

www.hindawi.com
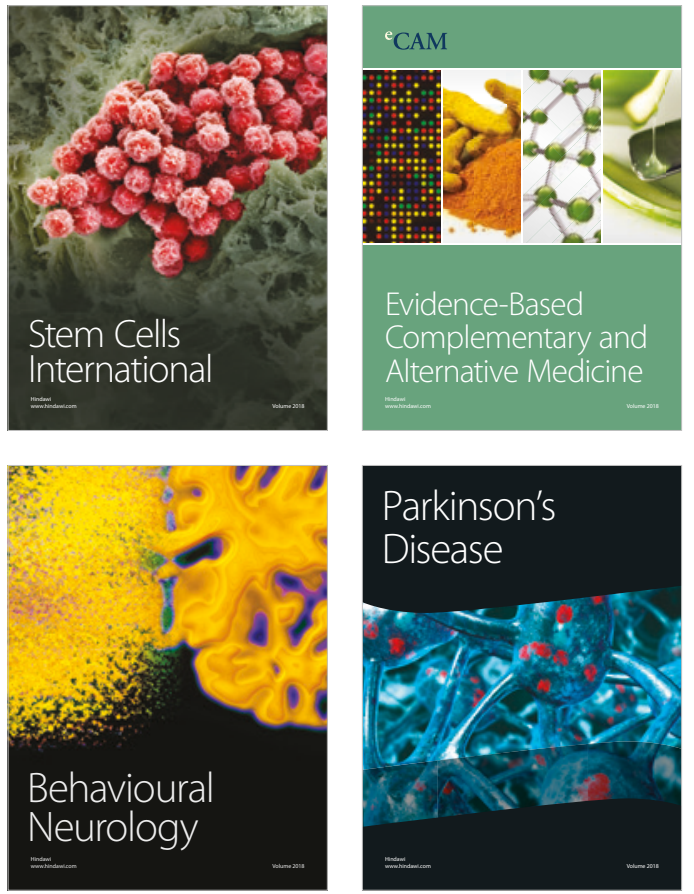

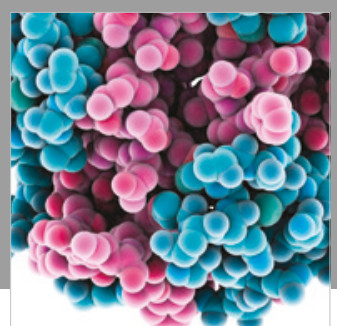

ournal of

Diabetes Research

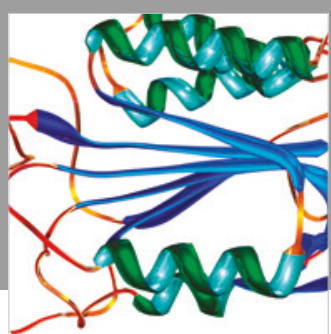

Disease Markers
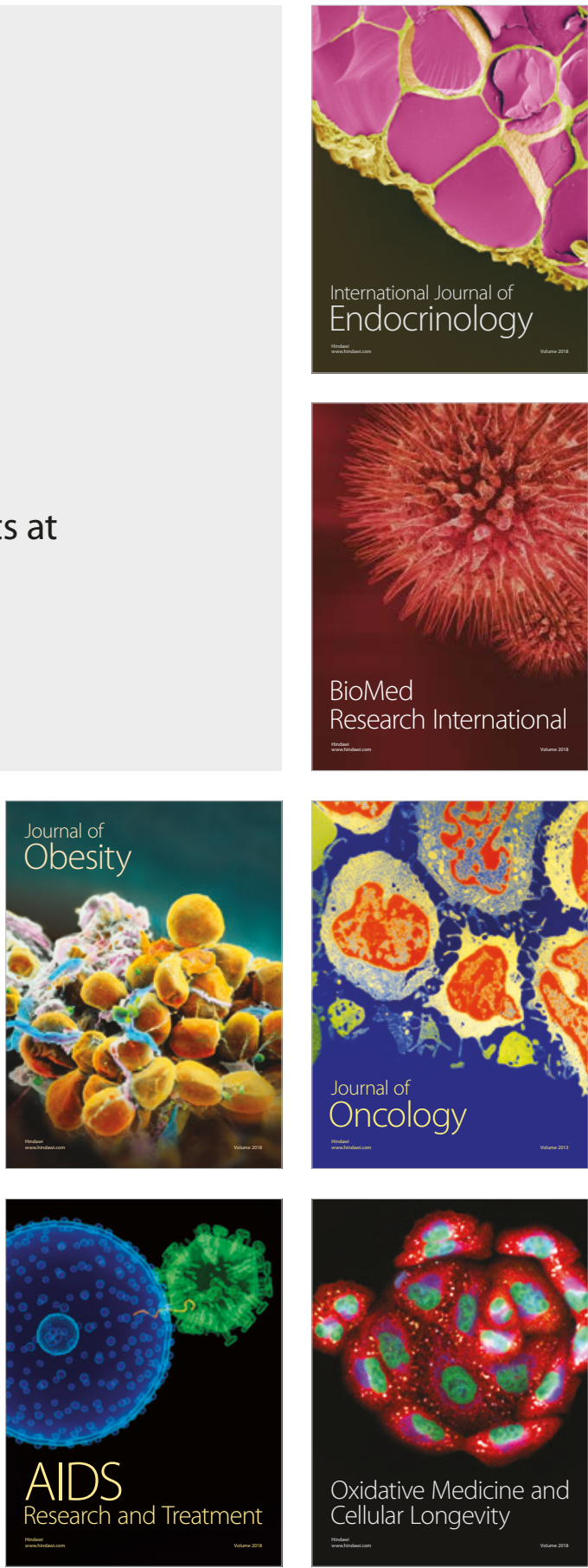